\title{
Implementation of e-health innovative technologies in North Lebanon hospitals
}

Jalal Halwani ${ }^{1}$ and Doris Mouawad ${ }^{1}$

${ }^{1}$ Lebanese University, Faculty of Public Health, Dam \& Farz, Tripoli, Lebanon (Correspondence to: J. Halwani: jhalwani@ul.edu.lb)

\begin{abstract}
Background: E-health is considered the single most important revolution in health care since the advent of modern medicine. It is an emerging field of medical informatics, used in the organization and delivery of health services and information. It is expected to improve various aspects of health care.
\end{abstract}

Aims: To achieve universal health coverage in Lebanon, and to explore e-health implementation in Northern Lebanese hospitals and factors influencing the adoption of recent specialized technology in e-health.

Methods: We adopted an exploratory research method based on a semi-structured questionnaire. The main 14 hospitals in Northern Lebanon were chosen for face-to-face interviews to assess and measure behaviour and knowledge regarding e-health and its implementation. Data were analysed using SPSS software, followed by SWOT analysis.

Results: The hospitals surveyed had partly implemented and continuously tried to apply some e-health technologies, but there were no real medical records for patients. Various challenges were faced for full e-health technology implementation in Lebanon: primarily cost, followed by some personnel resistance, lack of legislation and common standards, and the necessity for continual training.

Conclusion: The majority of hospitals are conscious of the importance of e-health technology and the urgent need to implement these new methods. After the legislative rules are issued, the financial aspects remain the major handicap to full implementation. A major role must be played by the academic institutions to provide appropriate education on e-health in their programmes for future graduates.

Keywords: e-health, health technology assessment, electronic health record, health academic institutions, Lebanon

Citation: Halwani J; Mouawad D. Implementation of e-health innovative technologies in North Lebanon hospitals. East Mediterr Health J. 2021;27(9):892898. https://doi.org/10.26719/emhj.21.030

Received: 05/05/20; accepted: 01/03/21

Copyright (C) World Health Organization (WHO) 2021. Open Access. Some rights reserved. This work is available under the CC BY-NC-SA 3.0 IGO license (https://creativecommons.org/licenses/by-nc-sa/3.o/igo)

\section{Introduction}

After the United Nations General Assembly's meeting in September 2015, in which it adopted the 2030 Agenda for Sustainable Development, member states renewed their commitment to promote the health and well-being of their populations with health care of good quality and affordable prices, and governments began working on attaining universal health coverage. However, they were faced with various issues regarding the choice of heath technology because it should satisfy the ethical, economical and organizational facets, and requires changes in health systems and the way they work. Additionally, the World Health Organization (WHO) has been working since 2015 on assisting countries to implement health technology assessment (HTA), which covers efficacy, cost, safety and legal aspects (1).

Lebanon, with the help of WHO, drafted its first HTA strategy in 2014 and is working on implementing both HTA and e-health within healthcare centres (2). Consequently, Hôtel-Dieu de France (HDF), a private hospital located in Beirut, became in October 2018 the first e-hospital in Lebanon with an integrated hospital information system (HIS). This system's major advantage combines 3 of the hospital's main components: the patient's complete medical files, financial operations files, and human resources management files. This helped HDF to optimize its internal processes and patient safety by: (1) applying and conforming to local and international accreditation and standards; (2) tracking patient progress from day 1 until discharge; (3) customizing care based on patient needs; and (4) automating and linking all ancillary departments to the centralized comprehensive HIS.

Lebanon is one of the most dynamic healthcare markets and has one of the best quality healthcare sectors in the Arab Region. It enjoys a growing health tourism and cosmetic surgery sector. Although the government does not accord the medical field a high proportion of GDP in comparison with other Arab countries, Lebanon continues to provide high-quality medical care at affordable prices (3). Medical procedures in Lebanon cost less than they do in Europe or the United States of America (4).

The adoption of e-health in Lebanon is still in its early phases; therefore, the rates of usage remain low, and the shift to e-health is necessary even if the country is not fully ready for it (5). This requires examination of the major factors interfering with implementation of e-health while stating its economic and social benefits. 
e-Health can also affect health outcomes as well as indicators; therefore, its implementation is crucial.

On the social level, HTA is required in countries that are undergoing economic transition such as Lebanon, due to the fact that e-health provides quality care to all patients. According to the Lebanese Ministry of Public Health (6), implementing this technology can have a major impact on poor people who will be able to receive healthcare services, especially as e-health allows contact between patients and doctors through text and voice messages, which reduces the costs. According to Lewis et al., $47 \%$ of the programme is donated by funders, and $34 \%$ of patients tend to use applications that allow voice messaging and 31\% use text messaging (7). The regular healthcare procedures have created a clash between rich and poor people within the same society. Private hospitals have the best medical services at the expense of high costs, while public hospitals have lower costs but unfortunately do not provide the best treatments. However, information and communication technology plays a major role in finding solutions for health equity problems. Thus, substituting healthcare procedures with e-health processes will allow more citizens to receive appropriate services. E-health allows better communication between medical staff and patients, and offers homeless and poor people quality care at affordable prices.

Artificial intelligence is mostly used in e-health; therefore, a large number of people can contact doctors, schedule appointments and run tests at the push of a button. Additionally, in developing countries, e-health offers children and uneducated women access to vaccines and medicine at low prices.

The implementation of technology in hospitals has allowed hospital systems to record all patients' information on digital systems. These electronic health records (EHRs) are automatically updated after every patient's visit and after receiving test results. Patients can

\begin{tabular}{lccc}
\hline \multicolumn{4}{l}{ Table 1 Names and localization of hospitals } \\
Number & Hospital & City & Caza \\
\hline 1 & Tripoli Governmental & Tripoli & Tripoli \\
2 & Mazloum & Tripoli & Tripoli \\
3 & Nini & Tripoli & Tripoli \\
4 & Al-Chifaa & Tripoli & Tripoli \\
5 & Monla & Tripoli & Tripoli \\
6 & Islamic & Tripoli & Tripoli \\
7 & Haykal & Ras Maska & Koura \\
8 & Koura & Aba & Koura \\
9 & Centre Hospitalier du & Zgharta & Zgharta \\
10 & Nord & & \\
11 & Saydet & Zgharta & Zgharta \\
12 & Family Medical Center & Zgharta & Zgharta \\
13 & Notre Dame Maritime & Jbail & Jbail \\
14 & Notre Dame de Secours & Jbail & Jbail \\
\hline
\end{tabular}

contact doctors living in a different continent and have consultations without moving from their homes (8). The EHR system is computerized and allows medical staff to enter patients' data in a digital manner to be accessed by the patients themselves or their doctors. HISs also keep records of patients' data, including data gathered by nurses before and after surgery and during recovery, and even allow billing and appointment scheduling (9).

Many countries, such as Lebanon, have paper-based medical records (10). Following e-health implementation, data recording uses computer systems that can be accessed by doctors at any time. Furthermore, it is possible to share the information with other doctors or healthcare centres upon request from the patient (11). E-health technology brings patients closer to healthcare centres, as they can contact laboratories through the laboratory information system, which transfers information directly to the patient's phone (12). This shift from paper-based to digital recording is beneficial for the environment too as it reduces paper consumption (13).

One of the benefits of e-health is that it allows hospital systems to record all patient information in EHRs. The difference between HISs and EHRs is important; the former refers to systems designed to manage healthcare data. This includes systems that collect, store, manage and transmit EHRs, a hospital's operational management, or systems supporting healthcare policy decisions. HISs also include those systems that handle data related to the activities of providers and health organizations. The shift from paper-based medical records to EHRs cannot be considered purely beneficial. For example, computer downtime, planned or unplanned, can put the entire electronic medical data and patient safety at risk (14).

\section{Methods}

In Lebanon, there are 147 hospitals contracted to the Ministry of Public Health (117 private and 30 public); 29 of them (21 private and 8 public) are in North Lebanon $(20 \%)$ (15). We selected 14 main hospitals and conducted face to face interviews with relevant staff (general managers, medical directors and information and communication technology managers) in March 2020. The study sample represented $\sim 50 \%$ of the total healthcare institutions in North Lebanon.

The interviews lasted for 30 minutes and tackled issues such as the impact of e-health on the community in general and on the relationship between patients and doctors, the risks and benefits of e-health, as well as future strategic plans to be implemented by the hospitals. We also distributed a semi-structured questionnaire to the representatives of the hospitals. Since the concept of e-health is new in Lebanon, and especially in North Lebanon, we assessed behaviour and knowledge regarding e-health and its implementation in healthcare facilities with the following main questions. (1) Can the implementation of e-health technologies affect the quality of a medical organization as well as its workflow? (2) Can the implementation of e-health 
influence the behaviour and attitudes of employees towards learning more about innovative technologies in the medical field? (3) Are positive results seen through the introduction of innovative technologies such as e-health and personal health records in medical organizations? (4) Can education, learning and training affect the implementation process in North Lebanon?

A SWOT analysis (strengths, weaknesses, opportunities, threats) on e-health implementation in North Lebanese hospitals was done to identify the impact of this new technology on health care and its acceptance by involved professionals.

All interview forms were verified and entered into an online database designed using XLS forms uploaded to ONA web forms for research surveys. All data were processed using SPSS version 22, and frequency tabulation of the total sample was provided. Excel charts based on the processed data were also generated.

The research methods and procedures used in this study conformed to ethical research standards and were approved by the Faculty Director. The research team adopted strict quality measures to ensure the reliability of their findings. In addition, this study respected the confidentiality of the data and protected the anonymity of the participants.

\section{Results}

\section{Implementation of $e$-health}

E-health has been partially applied in 13 of the 14 hospitals, depending on the hospital's sectors. It was mostly applied in healthcare services (31\%) as well as in hospital departments (23\%) (Figure 1). As a result, 13 of 14 hospitals already have a specialized department for e-health.

E-health applications are primarily represented by electronic health records (EHR) in hospital reception services $(17 \%)$, and the other applications such as pharmacy, laboratory services and radiography use only $8 \%$. Accordingly, we have found that all of them have partly implemented and have continuously tried to apply e-medicine and adopt EHRs, while telemedicine is still far behind with $8 \%$ only. More than $90 \%$ of patients have no digital card about their medical records (Figure 2), as digital cards are not operational in all hospitals, and patients who want a copy of their medical records can only obtain some information on paper.

Legal oversight of e-Health applications was highest for accreditations, with 7 of 14 hospitals abiding by them, while the Health Insurance Portability and Accountability Act (HIPPA) came last with only 1 hospital abiding by it. Each reimbursement fund (social security, cooperative of state officials, army, insurance company, etc.) has its own regulations. Eight of 14 hospitals had supervision over e-health by the Ministry of Public Health to ensure compliance with the system. Various other challenges are faced when implementing e-health in hospitals, such as cost, which was the leading challenge $(50 \%)$ followed by resistance of physicians (14\%) (Figure 3).

\section{SWOT analysis}

The SWOT analysis, by which we assess the strengths, weaknesses, opportunities and threats of e-health, is a useful and time-tested management tool. This technique has been adopted by hospitals due to its effective and simple methods, and it is appropriate to use in strategic planning in healthcare systems or medical innovations (16). Variables are divided into internal and external. Internal variables can be controlled within the hospital, such as strengths and weaknesses. External factors are typically things we do not control, but influence and affect the functioning of the system, whether they are connected directly or indirectly to an opportunity $(\mathrm{O})$ or threat $(\mathrm{T})$, and it is important to note and document each one. SWOT analysis makes it possible to clarify and distinguish these different variables in a list divided into grids 2 by 2 . Therefore, it allows medical centres to visualize and take advantage of threats and opportunities to improve their strengths and weaknesses.

To be well run and high performing, hospitals must be data driven. The first step of SWOT analysis in e-health is to collect and assess important data. This can range from patient health records and disease registries to claims statuses and funding sources. SWOT analysis is not entirely data driven, but data can be helpful in thinking about what we are good at and what areas need

Figure 1 Place of e-health activities. All services: everything in the hospital from reception to patient discharge. Hospital departments: nursing, accounting, human resources, etc.

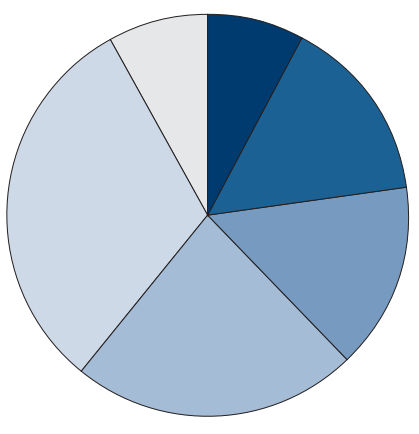

Special departaments for e-health implementation

All services

Hospital departments

Hospital services

Specialized clinics

Medical offices 
Figure 2 Chart of medical tools in hospitals

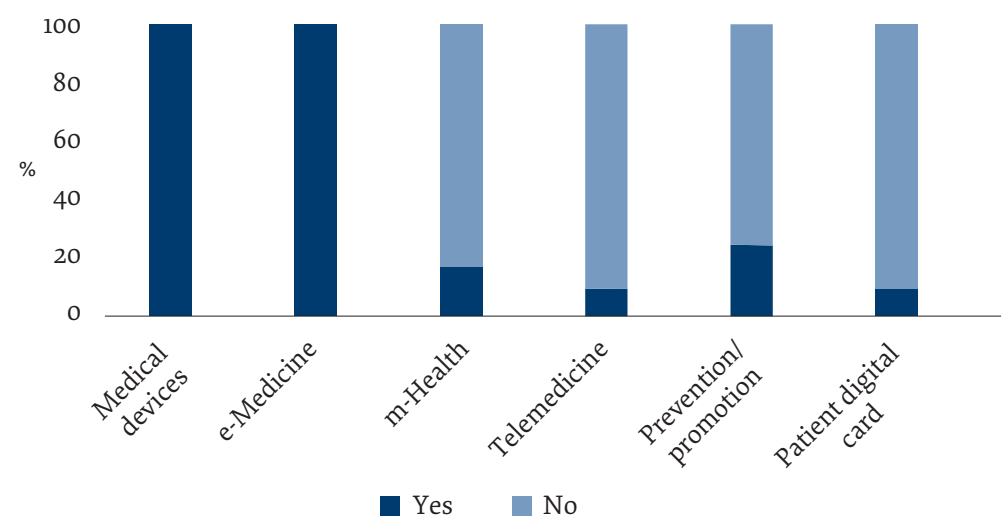

improvement. Figure 4 briefly presents our findings for the e-health implementation in North Lebanon.

\section{Discussion}

Our results are proof that e-health implementation is still in its early phases in Lebanon, and health professionals need to learn more about the technology in order to accept it. Hospitals need to provide adequate equipment to allow localized data recording through internet access. Our results can be generalized since many Lebanese hospitals, around 50\%, have not yet implemented e-health, HISs or EHRs. The Lebanese Government as well as the Lebanese Ministry of Health do not impose on hospitals the implementation of such tools. These results apply to all hospitals except for the 3 biggest hospitals in Beirut, namely, Hôtel Dieu, Clemenceau Medical Center and American University of Beirut Medical Center.

HTA can be used to evaluate sustainable healthcare systems (17). Since HTA is considered a new concept in Lebanon, a large number of medical staff lack fundamental knowledge about e-health. Therefore, Lebanon should conduct special training for medical and administrative staff to learn from those who have experience in this field. Academic institutions in Lebanon do not yet include e-health in their curricula, although the American University of Beirut has begun building an EHR system and relying on it (18). To train medical staff capable of implementing and working with e-health, academic institutions should introduce the concept of e-health in their academic programmes; a new e-health master's degree should be created for former graduates as part of lifelong learning (19). To move from classical to technology-based health care, the staff in Lebanese hospitals should learn about EHRs. An important measure would be to train medical staff, especially doctors, to use new technology and learn how to save the data and link them to digital medical records (20).

e-health innovation technologies provide various benefits for patients, medical centres, medical staff and stakeholders, such as providing quality care equally to all patients, and digital medical data recording, which can be considered a green solution.

The implementation of e-health cannot be carried out quickly, and many studies have explored the barriers

\section{Figure 3 Challenges concerning e-health}

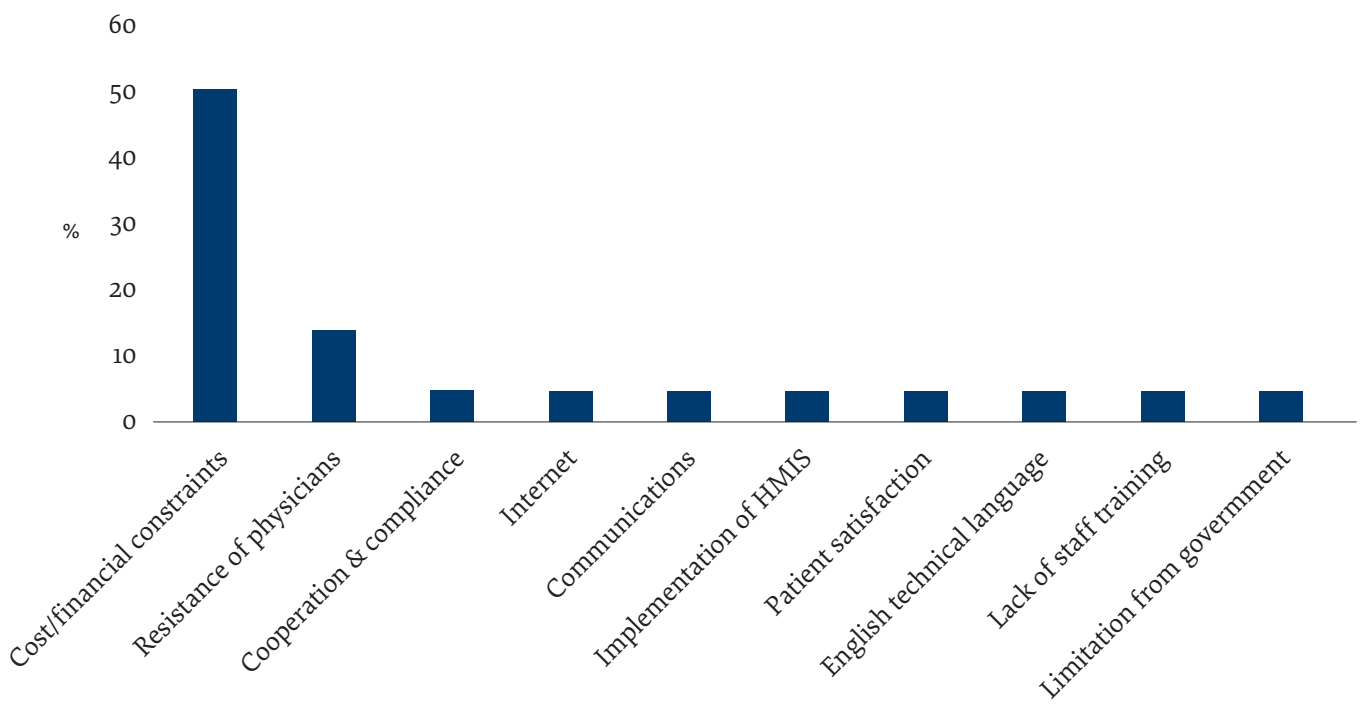




\begin{tabular}{|c|c|c|c|}
\hline Strengths & Weaknesses & Opportunities & Threats \\
\hline $\begin{array}{l}\text { - Advanced IT skills } \\
\text { - Use of programs such as EHR } \\
\text { apps } \\
\text { - High level of networking and } \\
\text { communication } \\
\text { - Funding capacity for training } \\
\text { and installation } \\
\text { - Classification of hospitals } \\
\text { according to specialism and } \\
\text { range of services } \\
\text { - Hospital administration } \\
\text { interested in the main topics }\end{array}$ & $\begin{array}{l}\text { Poor financing for devices; } \\
\text { high cost and new generation } \\
\text { network purchase } \\
\text { - Weak experience \& knowledge } \\
\text { of medical staff in the field } \\
\text { - Weakness in educational \& } \\
\text { technical skills in AI domain }\end{array}$ & $\begin{array}{l}\text { - Support from } \mathrm{MoPH} \text { and } \\
\text { medical professional } \\
\text { associations } \\
\text { - Implementation of deep } \\
\text { learning \& machine learning } \\
\text { in AI } \\
\text { - Funds to finance this project; } \\
\text { e.g., from individual donors and } \\
\text { industry grants } \\
\text { - Presence of companies and } \\
\text { institutions working on } \\
\text { implementing digitization \& } \\
\text { training skills }\end{array}$ & $\begin{array}{l}\text { - Difficulties in socioeconomic } \\
\text { conditions and political } \\
\text { situation } \\
\text { - Policy and legal protection } \\
\text { - Negative patient attitude } \\
\text { concerning privacy } \\
\text { - Hacker and denial-of-service } \\
\text { attack } \\
\text { - Weakness in network for } \\
\text { information sharing }\end{array}$ \\
\hline
\end{tabular}

to e-health adoption (21). One such barrier concerns the education and training of staff. In Lebanese academic institutions, there is no postgraduate diploma in e-health, and health disciplines do not include any e-health modules in their curricula. E-health is more than just electronic records; it is multidisciplinary in nature and concerns all people involved in health care. Therefore, it is important to create a postgraduate qualification in e-health for health professionals who wish to enhance their understanding and ability to work effectively with information and communication technologies. Another challenge for implementation of e-health is computer downtime for electronic data recording, which can be planned or unplanned; either way it puts the entire electronic medical data, as well as patient safety at risk.

E-health has great benefits in the medical sector, It has been shown that EHRs generate better quality of care and ambulatory services (22). However, the implementation of e-health and allowing automatic updates of medical data and sharing among physicians without the agreement of patients could have implications for patient privacy. Additionally, this new technology is in constant development; therefore there is a need for continual technical supervision.

\section{Conclusion}

The purpose of this study was to gather data about the information technology infrastructure in healthcare systems in North Lebanon hospitals. An explicit political commitment by the Lebanese Ministry of Public Health to adopting e-health is required. This commitment needs to be backed by sustainable funding for the implementation of e-health and actions for capacity building and evaluation that are aligned with a national strategy for e-health. Without the financial support and a legislative framework, the implementation of e-health in Lebanese hospitals will be compromised. The WHO Lebanon Office could play a major role in e-health implementation by supporting local initiatives or through capacity building in e-health technologies and sharing of global best practices and standards derived from successful e-health implementations.

Funding: None.

Competing interests: None declared.

\section{Mise en œuvre de technologies innovantes en cybersanté dans les hôpitaux du Liban-Nord \\ Résumé}

Contexte: La cybersanté est considérée comme la plus importante révolution dans le domaine des soins de santé depuis l'avènement de la médecine moderne. Il s'agit d'un domaine émergent de l'informatique médicale, utilisé dans l'organisation et la prestation de services et la fourniture d'informations sanitaires. Elle devrait permettre d'améliorer divers aspects des soins de santé.

Objectifs : Atteindre la couverture sanitaire universelle au Liban, et examiner la mise en œuvre de la cybersanté dans les hôpitaux du Liban-Nord et les facteurs influençant l'adoption d'une technologie spécialisée récente dans la cybersanté.

Méthodes: Nous avons adopté une méthode de recherche exploratoire basée sur un questionnaire semi-structuré. Les 14 principaux hôpitaux du Liban-Nord ont été choisis pour des entretiens en présentiel afin d'évaluer et de mesurer le comportement et les connaissances concernant la cybersanté et sa mise en œuvre. Les données ont été analysées à l'aide du logiciel SPSS, suivies d'une analyse AFOM (atouts, faiblesses, opportunités, menaces). 
Résultats : Les hôpitaux enquêtés ont partiellement mis en œuvre certaines technologies de cybersanté et essayent continuellement de les appliquer, mais il n'existe pas de véritables dossiers médicaux pour les patients. La mise en œuvre complète des technologies de cybersanté au Liban s'est heurtée à plusieurs obstacles : il s'agit en premier lieu du coût, suivi d'une certaine réticence du personnel, de l'absence de législation et de normes communes, et de la nécessité d'une formation continue.

Conclusions: La majorité des hôpitaux sont conscients de l'importance des technologies de cybersanté et de la nécessité urgente de mettre en œuvre ces nouvelles méthodes. Après la promulgation des règles législatives, les aspects financiers restent le principal frein à une mise en œuvre complète. Les établissements universitaires doivent jouer un rôle majeur pour fournir aux futurs diplômés un enseignement approprié sur la cybersanté dans leurs programmes.

$$
\text { تنفيذ تكنولوجيات الصحة الإلكترونية المبتكرة في مستشفيات شمال لبنان }
$$

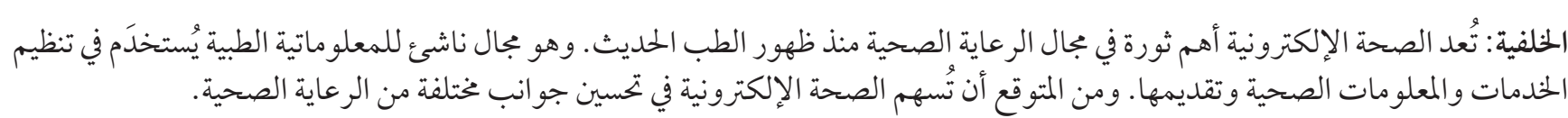

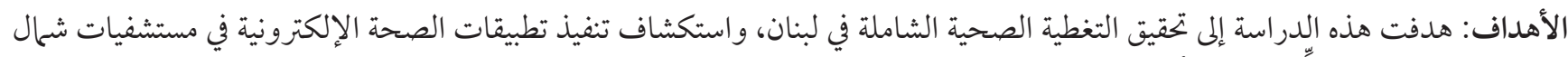

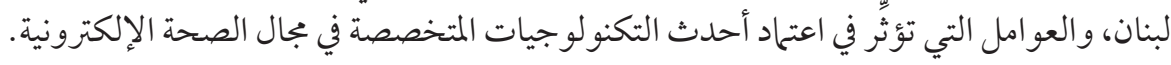

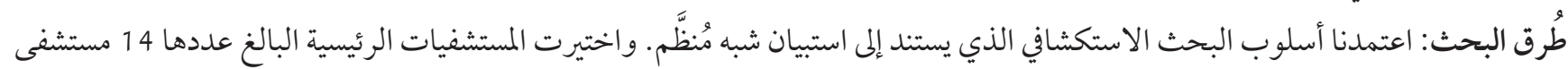

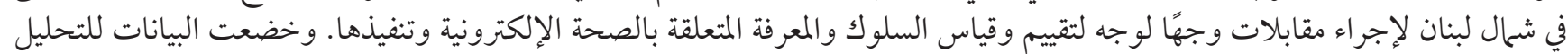

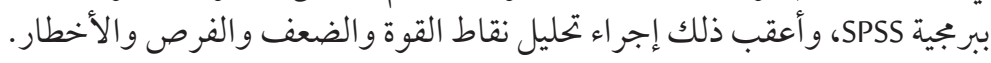

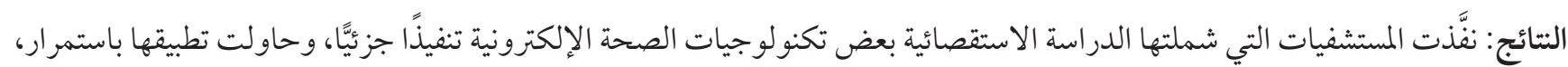

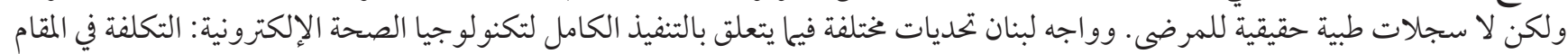

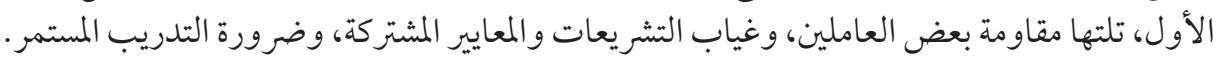

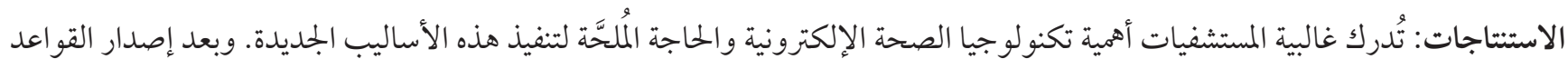

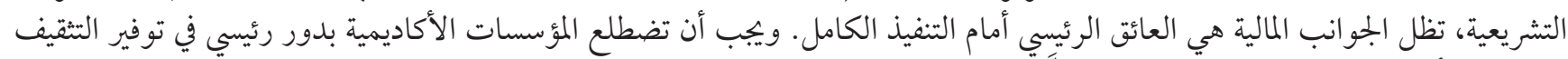

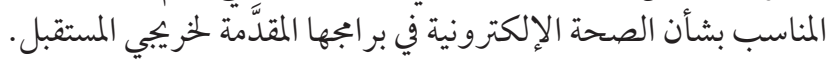

\section{References}

1. $\quad$ Nygren-Krug H. The right(s) road to universal health coverage. Health Hum Rights. 2019 Dec;21(2):215-28. PMID:31885451

2. Health strategic plan for the medium term (2016 to 2020). Beirut: Ministry of Public Health; 2016 (https://www.moph.gov.lb/en/ Pages/o/11665/strategic-plan-2016-2020-, accessed 27 April 2021).

3. Schellen T. (2018). A look into Lebanon's healthcare. Untangling myriad business strings. Executive. 6 August 2018 (https://www. executive-magazine.com/special-report/a-look-into-lebanons-healthcare, accessed 27 April 2021).

4. Hospitals in Lebanon. Banque Bemo; 2013 (http://www.databank.com.lb/docs/Hospital\%20Industry\%20Report.\%20June\%202013. pdf, accessed 27 April 2021).

5. New milestone towards e-health in Lebanon. Telecom Review. 19 April 2018 (https://telecomreview.com/index.php/articles/exclusive-interviews/2229-new-milestone-towards-e-health-in-lebanon, accessed 27 April 2021).

6. Abou Mrad, L. e-Health Initiative. Health insight 4 March 2014. Beirut: Ministry of Public Health; 2014 (https://www.moph.gov. lb/userfiles/files/Programs\%26Projects/NationalE-healthProgram/E-Health\%20Solutions-2014.pdf, accessed 29 April 2021).

7. Lewis T, Synowiec C, Lagomarsino G, Schweitzer J. E-health in low- and middle-income countries: findings from the Center for Health Market Innovations. Bull World Health Organ. 2012 May 1;90(5):332-40. https://doi.org/10.2471/BLT.11.099820 PMID:22589566

8. What is HER software? And must-have features for interoperability [website]. Forsee Medical; 2020 (https://www.foreseemed. com/blog/ehr-software-and-interoperability, accessed 29 April 2021).

9. Giokas D. EMR, EHR, and PHR - and Now aEMR and H/HIS what's with these systems? [website]. Canada Health Infoway; 2016 (https://www.infoway-inforoute.ca/en/what-we-do/blog/digital-health-records/7017-emr-ehr-and-phr-and-now-aemr-and-h-hiswhat-s-with-these-systems, accessed 29 April 2021). 
10. Ghabi E, Farah W, Abboud M, Habib LA, Chalhoub E, Ziade NR, et. al. (2019). Using paper based registries in studying the health effect of air pollution: case of Beirut. XIth International Epidemiological Association - Eastern Mediterranean Regional Scientific Meeting. Beirut; February 2019. (https://doi.org/10.13140/RG.2.2.36340.58241)

11. Uz Zaman T, Abdul Raheem T, Alharbi G, Shodri M, Kutbi A, Alotaib S., et al. E-health and its transformation of healthcare delivery system in Makkah, Saudi Arabia. Int J Med Res Health Sci. 2018;7(5):76-82. https://www.ijmrhs.com/medical-research/ ehealth-and-its-transformation-of-healthcare-delivery-system-in-makkah-saudi-arabia.pdf

12. Snyder C, Wu A, Miller R, Jensen R, Bantug E, Wolff A. The role of infographics in promoting patient-centered care. Cancer J. 2011;17(4):211-8. https://doi.org/10.1097/PPO.obo13e318225ff89

13. Click, C. (2017). How healthcare organizations can reduce their reliance on paper. Electronic Health Reporter. 1 May 2017 (https:// electronichealthreporter.com/healthcare-organizations-can-reduce-reliance-paper/, accessed 29 April 2021).

14. Schnell-Inderst P, Mayer J, Lauterberg J, Hunger T, Arvandi M, Conrads-Frank A, et al. Health technology assessment of medical devices: what is different? An overview of three European projects. Z. Evid. Fortbild. Qual. Gesundhwes. 2015;109(4-5):309-18. https://doi.org/10.1016/j.zefq.2015.06.011 PMID:26354131

15. Hamadeh G, Wakim JM, Romani A, Hamam H, Daher N, Nassar R, et al. Building consensus on the readiness for EHR in Lebanon. Are Lebanon hospitals ready to get rid of papers? Beirut: Ministry of Public Health Policy Support Observatory; 2019 (https://www.aub.edu.lb/fm/CME/Documents/EHR-Readiness/EHR\%2oreadiness\%20Lebanon\%2020190822\%20-\%20Reduced. pdf, accessed 29 April 2021).

16. Ruggeri K, Farrington C, Brayne C. (2012). A global model for effective use and evaluation of e-learning in health. Telemed J E Health. 2013 Apr;19(4):312-21. https://doi.org/10.1089/tmj.2012.0175 PMID:23472702

17. Pearl R. What health systems, hospitals, and physicians need to know about implementing electronic health records. Harvard Business Review. 15 June 2017 (https://hbr.org/2017/06/what-health-systems-hospitals-and-physicians-need-to-know-about-implementing-electronic-health-records, accessed 29 April 2021).

18. Larsen E, Fong A, Wernz C, Ratwani RM. Implications of electronic health record downtime: an analysis of patient safety event reports. J Am Med Inform Assoc. 2018 Feb 1;25(2):187-91. https://doi.org/10.1093/jamia/ocxo57 PMID:28575417

19. Statistical Bulletin 2018. Beirut: Ministry of Public Health; 2018 (https://www.moph.gov.lb/en/Pages/8/327/statistical-bulletins, accessed 29 April 2021).

20. Van Wijngaarden J, Scholten G, Van Wijk K. Strategic analysis for health care organizations: the suitability of the SWOTমanalysis. Int J Health Plann Manage. 2012 Jan-Mar; 27(1):34-49. https://doi.org/10.1002/hpm.1032 PMID:20603842

21. Razmak J, Al Shawabkeh A, Kharbat F, Qasim A. Examining the factors affecting the adoption of e-health innovative technology. Int J Econ Bus Res. 2018;16(2):196-209. https://doi.org/10.1504/IJEBR.2018.10014172

22. Zhou L, Soran C, Jenter C, Volk L, Oray J, Bates D, Simon S. The relationship between electronic health record use and quality of care over time. J Am Med Inform Assoc. 2009 Jul-Aug;16(4):457-64. https://doi.org/10.1197/jamia.M3128 PMID:19390094 